\title{
Religiosity/Spirituality and Mental Health: Psychiatric Staff's Attitudes and Behaviors
}

\author{
Eunmi Lee', Anne Zahn'2, Klaus Baumann' \\ ${ }^{1}$ Department of Caritas Science and Christian Social Welfare, Freiburg University, Freiburg, Germany \\ ${ }^{2}$ Department of Psychiatry and Psychotherapy, Freiburg University Hospital, Freiburg, Germany \\ Email: eunmi.lee@theol.uni-freiburg.de, anne.zahn@uniklinik-freiburg.de, \\ klaus.baumann@theol.uni-freiburg.de
}

Received August 2014

\begin{abstract}
Along with the bio-psycho-social model in patient-centered care, religiosity/spirituality (ReS) receives increasing attention from medical communities. Correspondingly, healthcare professionals' perspectives and their attitudes towards ReS receive increased attention, as their attitudes play a crucial role in the therapeutic process. In this context a nationwide study was conducted at German university hospitals and confessional clinics to find out what kind of attitudes psychiatrists and nurses have towards $\mathrm{ReS}$ in clinical settings. The respondents generally regarded dealing with religious/spiritual issues as appropriate, and also rated themselves to be ready to integrate ReS into therapies. Otherwise, most of the respondents underlined professional neutrality as preventing factor for an integration.
\end{abstract}

\section{Keywords}

Religiosity, Spirituality, Mental Health, Psychiatrists, Nurses, Germany

\section{Introduction}

In the domain of mental health and care, it is supposed to be a professional standard to consider patients' various dimensions of mental life as well as behavior and to reflect them in the therapeutic process. In patient-centered care, the bio-psycho-social model serves to clarify that all aspects of relevance are considered and integrated into therapy wholistically. Along with this emphasis on patients, religiosity/spirituality (ReS) recently receives increasing attention from medical communities. Although there are still various approaches on the definition as well as controversies about ReS, in contemporary empirical studies spirituality is frequently defined in broad terms as a search for the Sacred [1] or for some transcendent reality. This attention is facilitated particularly in the present age of globalization and multiculturalism, in which people with diverse ethnical, cultural and religious backgrounds live together. Such an increase of attention is visible in numerous empirical studies that explore the relationship between ReS and physical as well as mental health [2]-[7].

Notwithstanding several studies which reveal negative effects of ReS on psychiatric patients [2] [8], most studies show a positive relation of ReS to mental health, e.g. inverse association with depression [9]-[11], suicide [12] or eating disorder [13]. For instance, a research of Asian Americans conducted by Ai and her colleagues 
showed that religious attendance significantly predicted a lower chance of major depression, even after controlling for other possible predictors [9]. In this correlation the mediating effect of social support was particularly recognized.

Another crucial factor driving strong attention to ReS in therapies are the religious/spiritual needs which psychiatric patients express in times of illness [14]-[17]. They opine that their healthcare providers should be aware of their patients' ReS, including to inquire about religious affiliations and/or religious/spiritual beliefs and to talk with patients about religious/spiritual topics without negative prejudice. Mental health professionals also reported that psychiatric patients mentioned religious/spiritual issues in clinics [18]. Acknowledging such needs and behaviors of patients, the importance of religiously/spiritually sensitive care in medical training and educational programs has been gradually emphasized including mental health professions [19].

Correspondingly, mental health professionals' perspectives and their attitudes towards ReS receive more attention. Healthcare providers' attitudes play an important role in the therapeutic relationship and process, such as medical decisions, clinical concepts or therapy integration. However, the number of studies which addressed mental health professionals in this regard is relatively small and the majority of them has been conducted in English-speaking countries, especially in the USA. Such studies show that mental health professionals are less familiar with religious/spiritual issues [20]-[23], while their personal religious/spiritual attitudes unconsciously co-determine the way they deal with ReS in clinical settings [21]-[27]. To further investigate such findings we conducted a nationwide study with psychiatric staff, both physicians and nurses, in Germany.

\section{Design and Methods}

\subsection{Objectives}

The target of this study was to find out what kinds of attitudes influence the way psychiatric staff, both physicians and nurses, deal with ReS in the therapeutic context. Our main questions were:

1) What kinds of attitudes do psychiatric staff have towards ReS in clinical settings?

2) How does psychiatric staff deal with religious/spiritual issues in the context of a therapy?

These questions were tested with a focus on two professions, psychiatrists and nurses, to verify if there is any occupational difference.

\subsection{Respondents}

This study focused on the departments of psychiatry and psychotherapy in German university hospitals and confessional clinics within the same cities. With a letter of information and an example of the questionnaire 53 clinics were addressed to participate in the study, of which 21 clinics agreed to take part in the survey. Overall, 12 of 32 university hospitals and 9 of 21 confessional clinics participated in this survey. The medical directors of the participating clinics distributed a paper-based questionnaire to staff directly working with patients in psychiatric fields, such as psychiatrists, psychotherapists, nurses or social workers.

Over a period of five months, 404 of 1654 questionnaires were returned resulting in a response rate of $24.43 \%$. For the purpose of our analysis, we concentrated on psychiatrists and nurses. A total of 283 questionnaires (70.6\%) had been filled out by these two professions. A response rate of the different professions could not be calculated, as solely the total number of psychiatric staff of each participating clinic could be obtained at the beginning of the survey. Because of insufficient responses only 249 questionnaires were used for the analysis.

\subsection{Instruments}

In our survey the primarily used instrument was a revised version of F. Curlin and his colleagues' questionnaire on Religion and Spirituality in Medicine: Physicians' Perspectives. This questionnaire intends to explore how physicians observe the influence of patients' ReS on health, and what kind of attitudes as well as self-reported behaviors regarding religious/spiritual issues in clinical setting they have. Curlin and his team developed this questionnaire based on literature research/investigation as well as several qualitative pilot interviews, and it was tested via multiple iterations of expert panel review [22].

In 2009 a local pilot study had been accomplished using this instrument [27]. Prior to the pilot study, items were translated from English into German and wordily revised by a team composed of theological and mental health professionals to reflect the environment of a mental health setting. Our German version includes addi- 
tional improvements according to respondents' comments of the pilot study [25]. Overall, each response category regarding staff's attitudes as well as self-reported behaviors to ReS was modified to a 5-point scale (from definitely not true to definitely true of me). The final version was reviewed by a professional team again to ensure consistent results. The questions about staff's attitudes as well as self-reported behaviors are fully described in Table 2.

\subsection{Statistical Analysis}

The data were analyzed using SPSS 20.0 for windows. To analyze the difference according to subgroups, the Pearson Chi-Square-Test as well as Fisher's Exact Text, T-Test as well as Levene's Test were used. Significance level was set at $p<0.05$.

\section{Results}

On average the respondents were 39.41 (range: 20 - 61) years old (Table 1). Of all respondents, about 58\% were women. More than the half of respondents have been nursing staff. $68.3 \%$ have a religious affiliation (among them $36.9 \%$ are Protestants and $25.3 \%$ Catholic; data not shown). Slightly more than 50\% worked in confessional clinics. According to professions, ca. $70 \%$ of nurses were women, while female psychiatrists were $44.2 \%$ (data not shown). Furthermore, $72.1 \%$ of the responding nurses worked in a faith-based clinic, whereas $64.2 \%$ of the responding psychiatrists were engaged in a university hospital. In terms of confession they did not show any noticeable differences.

To each question about psychiatric staff's attitudes as well as self-reported behaviors, a response category with a 5-point ordinal scale was offered. In the analysis of each item's mean, the translated answer "unsure" was removed to ensure that the nature of the ordinal scale was not affected in German version, as the German response can mean both "I am not sure" and "I have no idea". Therefore, the possible mean scores could range from 1.0 to 4.0. Solely the occupational significant difference was additionally tested including the reply "unsure” to avoid any loss of information. It yielded no further significant difference.

Table 1. Characteristics of survey respondents.

\begin{tabular}{cc}
\hline Variable & Values (\%) \\
\hline Absoulute number & 249 \\
Age (years) & $39.41 \pm 10.05$ \\
Clinic & \\
University hospitals & $120(48.2)$ \\
Faith-based clinics & $129(51.8)$ \\
Profession & \\
Psychiatrists & $113(45.4)$ \\
Nurses & $136(54.6)$ \\
Sex & $144(57.8)$ \\
Women & $105(42.2)$ \\
Men & \\
Denomination & $79(31.7)$ \\
No religious affiliation & \\
Have a religious affilication & $170.3)$ \\
\hline
\end{tabular}

\footnotetext{
${ }^{a}$ Atheist, agnostic, and none.
} 


\subsection{Psychiatric Staff's Attitudes towards Patients' Religiosity/Spirituality}

The respondents generally regarded questions about patients' religious/spiritual backgrounds as appropriate ( $m=$ $3.14 \pm 0.85$ ). Furthermore, almost $90 \%$ of the respondents had the opinion that it is generally appropriate to discuss religious/spiritual issues when a patient addresses these issues (48.6\% definitely true and $40.2 \%$ trends to be true; data not shown). On the other hand, a majority of respondents indicated that it is not appropriate to share staff's own religious/spiritual ideas ( $m=1.89 \pm 0.85)$ or to pray together with patients $(m=1.58 \pm 0.80)$. In particular, more than half of the respondents regarded prayer with a patient as absolutely incorrect behavior.

In comparison between the two professions, psychiatrists and nurses showed a similar opinion about the inquiry and discussion. In contrast, sharing staff's own religious/spiritual beliefs and ideas as well as prayers with patients were indicated more as appropriate by nurses than psychiatrists (shown in Table 2).

\subsection{Psychiatric Staff's Self-Reported Behaviors with Religious/Spiritual Issues}

With regard to the questions about their behaviors when patients address religious/spiritual issues, psychiatric staff usually replied that they are open as well as ready to deal with such issues. In line with professional desirability, the majority of respondents claimed that they listen very carefully and empathetically when religious/ spiritual issues are brought up by their patient $(m=3.71 \pm 0.50)$. They do not tend to change away from such an issue ( $m=1.96 \pm 0.80$ ), and they hardly assume that ReS is not their responsibility ( $m=1.76 \pm 0.90)$. Yet they were not willing to share their own religious/spiritual ideas and experiences $(m=1.80 \pm 0.87)$.

Interestingly, psychiatrists and nurses answered differently to several questions. For instance, psychiatrists are more ready to encourage their patients to practice patients' own religious/spiritual activities. Nurses, on the other hand, are more inclined to change away from religious/spiritual themes and suggest their patients to seek chaplains at a higher rate than psychiatrists (shown in Table 2). However, nurses answered they were sharing their own religious/spiritual ideas as well as praying with patients more frequently.

As last question, psychiatric staff was asked which factors might prevent them from dealing with religious/spiritual issues with psychiatric patients. Based on qualitative explorations in our pilot study which had

Table 2. Staff's attitudes and self-reported behaviors to religiosity/spirituality.

\begin{tabular}{|c|c|c|c|}
\hline \multirow{2}{*}{ Questionnaire items } & \multicolumn{3}{|c|}{ Mean $^{\mathrm{a}}$} \\
\hline & Psychiatrists & Nurses & $p$ \\
\hline \multicolumn{4}{|l|}{ Attitudes } \\
\hline $\begin{array}{l}\text { In general, it is appropriate for staff to inquire about } \\
\text { a patient's religion and/or spirituality. }\end{array}$ & $3.16 \pm 0.81$ & $3.13 \pm 0.89$ & n.s. \\
\hline $\begin{array}{l}\text { In general, it is appropriate for staff to discuss religious/spiritual issues, } \\
\text { when a patient brings them up. }\end{array}$ & $3.45 \pm 0.62$ & $3.37 \pm 0.73$ & s. \\
\hline $\begin{array}{l}\text { In general, it is appropriate for staff to talk about his or her } \\
\text { own religious beliefs and experiences with a patient. }\end{array}$ & $1.74 \pm 0.74$ & $2.02 \pm 0.91$ & 0.013 \\
\hline In general, it is appropriate for staff to pray with a patient together. & $1.30 \pm 0.50$ & $1.82 \pm 0.93$ & $<0.001$ \\
\hline \multicolumn{4}{|l|}{ Self-reported behaviors ${ }^{\mathrm{b}}$} \\
\hline I listen carefully and empathetically. & $3.76 \pm 0.45$ & $3.67 \pm 0.53$ & n.s. \\
\hline I try to change the subject in a tactful way. & $1.83 \pm 0.78$ & $2.06 \pm 0.81$ & 0.026 \\
\hline I encourage patients in their own religious/spiritual beliefs and practices. & $3.19 \pm 0.66$ & $2.88 \pm 0.81$ & 0.002 \\
\hline I respectfully share my own religious ideas and experiences. & $1.59 \pm 0.73$ & $1.98 \pm 0.95$ & 0.001 \\
\hline I pray with the patient. & $1.13 \pm 0.36$ & $1.63 \pm 0.89$ & $<0.001$ \\
\hline I refer patients to chaplains. & $2.95 \pm 0.73$ & $3.48 \pm 0.55$ & $<0.001$ \\
\hline It is not my responsibility. & $1.76 \pm 0.83$ & $1.77 \pm 0.97$ & n.s. \\
\hline
\end{tabular}

${ }^{\text {a }}$ Response categories are 1 = definitely not true, 2 = tends not to be true, 3 = tends to be true, 4 = definitely true of me. ${ }^{\text {b Preceded by }}$ "when religious/spiritual issues come up in discussions with patients." 
been conducted at the university hospital of Freiburg, we added several factors such as "professional neutrality" or "not my responsibility". For this item, it was possible to give multiple answers.

The most frequently mentioned reason is professional neutrality (45.4\%), followed by the lack of time and insufficient knowledge (respectively $29.3 \%$ and 22.5\%; data not shown). Furthermore, we tested occupational difference (Figure 1). Psychiatrists indicated professional neutrality more frequently than nurses (54.9\% vs. 37.5\%; $p=0.0006$ ), even though professional neutrality was a factor which mostly prevents both professional groups from dealing with religious/spiritual issues. Insufficient knowledge was the second factor mentioned most frequently by nursing staff (28.7\%), whereas only $15 \%$ of psychiatrists indicated this factor $(p=0.010)$. A lack of time was the second most frequent factor mentioned by psychiatrists.

\section{Discussion}

This study aimed to find out how groups of German mental health professionals, psychiatrists and nurses, deal with religious/spiritual issues, when patients address these topics, and whether these two professions show any difference. Through a nationwide study in Germany several results were discovered.

To start with, our respondents generally regarded dealing with religious/spiritual issues as appropriate when patients address such topics. They considered themselves to be open as well as ready to integrate ReS in clinical encounter, such as a talking with patients about religious/spiritual themes. Such a positive opinion on appropriateness or openness to religious/spiritual issues in therapy limited to talking about ReS and does not extend to practicing and hardly to encouraging religious/spiritual activities like prayer. Another noticeable point is that most respondents emphasized to be neutral in their professional activities. Approximately $45 \%$ of respondents underlined professional neutrality as decisive reason why it is difficult for them to integrate religious/spiritual issues in therapeutic settings. Furthermore, this statement is remarkably often cited by psychiatrists. The insufficient knowledge and lack of time were other repeatedly mentioned reasons.

There is an ongoing debate about ReS in clinical settings, especially with regard to the way of integration of ReS into psychiatric therapeutic processes. In a patient-centered care, it is important to recognize that religious/ spiritual desires of patients are increasing. According to the results of our study, the development of an appropriate understanding of professional neutrality is needed to empower psychiatric staff for an adequate inclusion rather than exclusion of mental and behavioral aspects of ReS both of their patients and themselves into treatment in a reflected and responsible way in an increasingly diversified and multicultural bio-psycho-social reality to foster harmony and respect of diversity. Furthermore, a considerable amount of staff reports inability to adequately handle ReS of patients, because of insufficient knowledge and a lack of appropriate training. In this sense, our study suggests that training programs should address more religious/spiritual issues. Through such training programs psychiatric staff can increase their self-awareness and learn to better understand possible influences (negative as well as positive) of ReS in the context of psychiatry and psychotherapy. Moreover, a supplementary analysis of our research shows that nurses who mentioned insufficient knowledge and concerns about offending patients as a preventing factor, have a stronger tendency to turn away from religious/spiritual

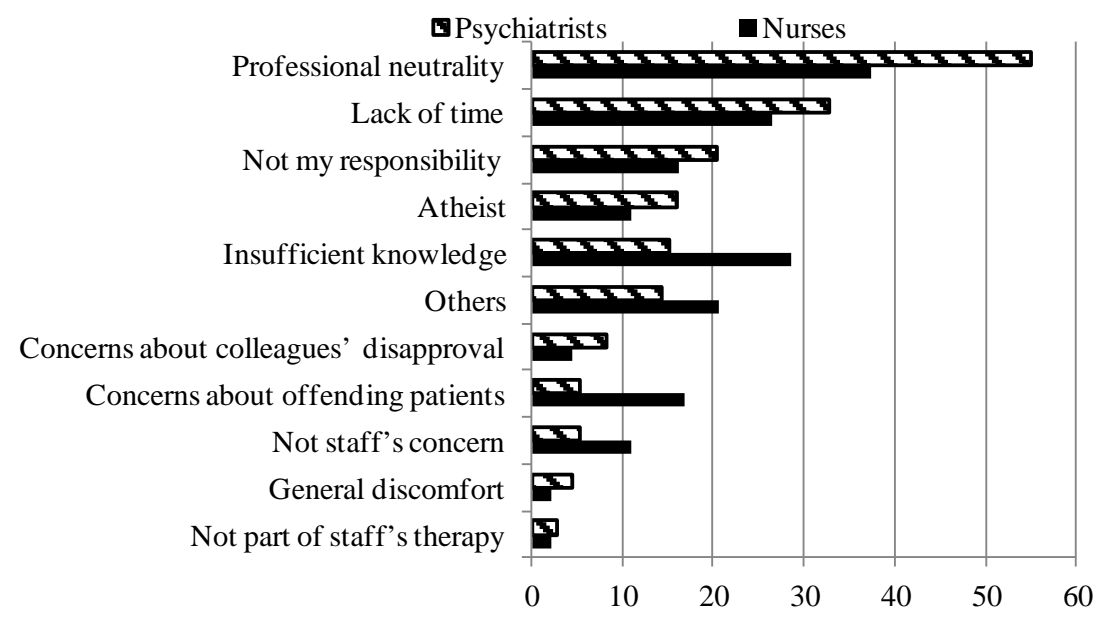

Figure 1. Factors preventing the staff from dealing with religiosity/spirituality. 
topics as well as to refer patients to chaplains. Nurses have more contact to patients and they spend more time with patients than psychiatrists [28]. Effective teamwork including an efficient exchange of information about patients will enable psychiatric professionals, who are not familiar with ReS, to better respond to such matters, at least e.g. adequate referral to other coworkers such as clinical chaplains or effective information about related programs.

Along with meaningful results, our study has certain limitations: First of all, our survey focused on departments of psychiatry and psychotherapy. For a more representative and comprehensive understanding, further studies with psychiatrists and nurses working in other departments like psychosomatics or geriatrics should be conducted. Secondly, participation was asked to clinical directors only, hence their personal concerns could influence the participation of clinics. Thirdly, the used questionnaire is a revised version from English to German. In the process of the translation, there have been necessary contextual modifications. Considering these limitations further studies are vital.

In the medical care services it is a golden rule to treat patients as a whole-person. Religious/spiritual issues are essential elements of mental and behavioral life for many patients and professionals. To neglect or actively exclude them in the context of mental health care and behavioral therapies seems to be a professional self-contradiction with consequences for the therapeutic process, even more though in multicultural and multi-ethnic societies which aim at harmony and mutual respect.

\section{Acknowledgements}

We sincerely thank all participants of our survey. Further, we would like to express our gratitude to Prof. Dr. med. Mathias Berger (Dept. of Psychiatry and Psychotherapy, University Hospital Freiburg) for his effective cooperation.

\section{References}

[1] Hill, P.C. and Pargament, K.I. (2008) Advances in the Conceptualization and Measurement of Religion and Spirituality: Implications for Physical and Mental Health Research. Psychology of Religion and Spirituality, S, 3-17. http://dx.doi.org/10.1037/1941-1022.S.1.3

[2] Huang, C.L.-C., Shang, C.-Y., Shieh, M.-S., Lin, H.-N. and Su, J.C.-J. (2011) The Interactions between Religion, Religiosity, Religious Delusion/Hallucination, and Treatment-Seeking Behavior among Schizophrenic Patients in Taiwan. Psychiatry Research, 187, 347-353. http://dx.doi.org/10.1016/j.psychres.2010.07.014

[3] Lucchetti, G., Lucchetti, A.L.G. and Koenig, H.G. (2011) Impact of Spirituality/Religiosity on Mortality: Comparison with Other Health Interventions. Explore, 7, 234-238. http://dx.doi.org/10.1016/j.explore.2011.04.005

[4] Miller, L., Bansal, R., Wickramaratne, P., Hao, X., Tenke, C.E., Weissman, M.M. and Peterson, B.S. (2014) Neuroanatomical Correlates of Religiosity and Spirituality: A Study in Adults at High and Low Familial Risk for Depression. JAMA Psychiatry, 71, 128-135. http://dx.doi.org/10.1001/jamapsychiatry.2013.3067

[5] Nazarzadeh, M., Sarokhani, M. and Sayehmiri, K. (2014) The Relationship between Religious Attitudes, Fear of Death and Dying with General Health Condition: A Survey in College Students. Journal of Religion and Health, June.

[6] Seyringer, M.-E., Friedrich, F., Stompe, T., Frottier, P., Schrank, B. and Frühwald, S. (2007) The “Gretchen Question” for Psychiatry_-The Importance of Religion and Spirituality in Psychiatric Treatment. Neuropsychiatrie, 21, 239-247.

[7] Unterrainer, H.F., Lewis, A.J. and Fink, A. (2014) Religious/Spiritual Well-Being, Personality and Mental Health: A Review of Results and Conceptual Issues. Journal of Religion and Health, 53, 382-392. http://dx.doi.org/10.1007/s10943-012-9642-5

[8] Lee, S.A., Roberts, L.B. and Gibbons, J.A. (2013) When Religion Makes Grief Worse: Negative Religious Coping as Associated with Maladaptive Emotional Responding Patterns. Mental Health, Religion \& Culture, 16, 291-305. http://dx.doi.org/10.1080/13674676.2012.659242

[9] Ai, A.L., Hall, D., Pargament, K. and Tice, T.N. (2013) Posttraumatic Growth in Patients who Survived Cardiac Surgery: The Predictive and Mediating Roles of Faith-Based Factors. Journal of Behavioral Medicine, 36, 186-198. http://dx.doi.org/10.1007/s10865-012-9412-6

[10] Baetz, M., Larson, D.B., Marcoux, G., Bowen, R. and Griffin, R. (2002) Canadian Psychiatric Inpatient Religious Commitment: An Association with Mental Health. The Canadian Journal of Psychiatry, 47, 159-166.

[11] Wei, D. and Liu, E.Y. (2013) Religious Involvement and Depression: Evidence for Curvilinear and Stress-Moderating Effects among Young Women in Rural China. Journal for the Scientific Study of Religion, 52, 349-367.

http://dx.doi.org/10.1111/jssr.12031 
[12] Rasic, D., Robinson, J.A., Bolton, J., Bienvenu, O.J. and Sareen, J. (2011) Longitudinal Relationships of Religious worship Attendance and Spirituality with Major Depression, Anxiety Disorders, and Suicidal Ideation and Attempts: Findings from the Baltimore Epidemiologic Catchment Area Study. Journal of Psychiatric Research, 45, 848-854. http://dx.doi.org/10.1016/j.jpsychires.2010.11.014

[13] Boisvert, J.A. and Harrell, W.A. (2013) The Impact of Spirituality on Eating Disorder Symptomatology in Ethnically Diverse Canadian Women. International Journal of Social Psychiatry, 59, 729-738. http://dx.doi.org/10.1177/0020764012453816

[14] D’Souza, R. (2002) Do Patients Expect Psychiatrists to Be Interested in Spiritual Issues? Australasian Psychiatry, 10, 44-47. http://dx.doi.org/10.1046/j.1440-1665.2002.00391.x

[15] Knox, S., Catlin, L., Casper, M. and Schlosser, L.Z. (2005) Addressing Religion and Spirituality in Psychotherapy: Clients’ Perspectives. Psychotherapy Research, 15, 287-303. http://dx.doi.org/10.1080/10503300500090894

[16] Koslander, T. and Arvidsson, B. (2007) Patients' Conceptions of How the Spiritual Dimension Is Addressed in Mental Health Care: A Qualitative Study. Journal of Advanced Nursing, 57, 597-604. http://dx.doi.org/10.1111/j.1365-2648.2006.04190.x

[17] Lawrence, R.M., Head, J., Christodoulou, G., Andonovska, B., Karamat, S., Duggal, A., Hillam, J. and Eagger, S. (2007) Clinicians’ Attitudes to Spirituality in Old Age Psychiatry. International Psychogeriatrics, 19, 962-973. http://dx.doi.org/10.1017/S1041610206004339

[18] Hofmann, L. and Walach, H. (2011) Spirituality and Religiosity in Psychotherapy-A Representative Survey among German Psychotherapists. Psychotherapy Research, 21, 179-192. http://dx.doi.org/10.1080/10503307.2010.536595

[19] Laboprabhu, S. and Lomax, J. (2010) The Role of Spirituality in Medical School and Psychiatry Residency Education. International Journal of Applied Psychoanalytic Studies, 7, 180-192. http://dx.doi.org/10.1002/aps.241

[20] Bergin, A.E. and Jesen, J.P. (1990) Religiosity of Psychotherapists: A National Survey. Psychotherapy, 27, 3-7. http://dx.doi.org/10.1037/0033-3204.27.1.3

[21] Baetz, M., Griffin, R. and Bowen, R. (2004) Spirituality and Psychiatry in Canada: Psychiatric Practice Compared with Patient Expectations. Canadian Journal of Psychiatry, 49, 265-271.

[22] Curlin, F.A., Lawrence, R.E., Odell, S., Chin, M.H., Lantos, J.D., Koenig, H.G. and Meador, K.G. (2007) Religion, Spirituality, and Medicine: Psychiatrists' and Other Physicians’ Differing Observations, Interpretations, and Clinical Approaches. The American Journal of Psychiatry, 164, 1825-1831. http://dx.doi.org/10.1176/appi.ajp.2007.06122088

[23] Curlin, F.A., Chin, M.H., Sellergren, S.A., Roach, C.J. and Lantos, J.D. (2006) The Association of Physicians’ Religious Characteristics with Their Attitudes and Self-Reported Behaviors Regarding Religion and Spirituality in the Clinical Encounter. Medical Care, 44, 446-453.

[24] Delaney, H.D., Miller, W.R. and Bisonó, A.M. (2007) Religiosity and Spirituality among Psychologists: A Survey of Clinician Members of the American Psychological Association. Professional Psychology: Research and Practice, 38, 538-546. http://dx.doi.org/10.1037/0735-7028.38.5.538.

[25] Lee, E. (2014) Religiosität bzw. Spiritualität in Psychiatrie und Psychotherapie. Ihre Bedeutung für psychiatrisches Wirken aus der Sicht des psychiatrischen Personals anhand einer bundesweiten Personalbefragung. Echter Verlag, Würzburg.

[26] Lee, E. and Baumann, K. (2013) German Psychiatrists’ Observation and Interpretation of Religiosity/Spirituality. Evidence-Based Complementary and Alternative Medicine, 2013, 1-8. http://dx.doi.org/10.1155/2013/280168

[27] Lee, E., Zahn, A. and Baumann, K. (2011) “Religion in Psychiatry and Psychotherapy?” A Pilot Study: The Meaning of Religiosity/Spirituality from Staff's Perspective in Psychiatry and Psychotherapy. Religions, 2, 525-535. http://dx.doi.org/10.3390/rel2040525

[28] Albers, G., Francke, A., de Veer, A.J.E., Bilsen, J. and Onwuteaka-Philipsen, B.D. (2014) Attitudes of Nursing Staff towards Involvement in Medical End-of-Life Decisions: A National Survey Study. Patient Education and Counseling, 94, 4-9. http://dx.doi.org/10.1016/j.pec.2013.09.018 